\title{
Evaluation of lifestyle of middle age people related to obesity
}

\begin{abstract}
Obesity is one of the most common and serious issue on people related to health problems. A study was conducted in Kachipuram Dist, Tamil Nadu, and India from July 2015 to June 2016 with a group of 200 patients. The results suggested that family history of obesity is important predictive variables for middle age obesity, rather than other related factors.
\end{abstract}

Keywords: obesity, middle age group, family history, hypertension
Volume 8 Issue I - 2018

Vasukidevi Ramachandran

Department of Biomedical Engineering, Bharath Institute of Science, India

\author{
Correspondence: Vasukidevi Ramachandran, Associate \\ Professor, Department of Biomedical Engineering, Bharath \\ Institute of Science and Technology, Chennai-600073, I73, \\ Agaram Road, Selaiyur,Tamil Nadu, India, \\ Email vasukideviram@gmail.com
}

Received: July 12, 2017 | Published: January 04, 2018

\section{Introduction}

Obesity among people is one of the most common issue and is a serious chronic diseases associated with other diseases. (i.e., cardiovascular disease, T2DM, hypertension, and some of cancer). Although both genetic and environmental issues are the major causes of overweight, the more likely prevalence worldwide is likely to be closely associated with changes in environmental factors in 1999-2000. ${ }^{1-3}$ The objective of this study was to assess the current prevalence of obesity and risk factors in adults. ${ }^{3-6}$ This study was conducted to assess the prevalence of obesity as well as of obesity risk and non obesity among the middle age group of the selected people. The family history, BMI and family history +BMI of obesity were also assessed.

\section{Methods}

This study is from a population-based in Kachipuram Dist, Tamil Nadu, and India from July 2015 to June 2016. The target population consisted of 25-45 aged males and females groups living in (give the place name) Tamil Nadu India. For the purpose of this study the men and women were compiling into groups, with individuals within these groups comprising the final sample units. Pregnant women were not considered in this study. The final sample was 200 (100 participation). Samples were analysed and limited to adult participants aged 25 - 45 aged groups. This sample size was considered sufficient to detect risk obesity and non obesity risk $100 \%$ confidence. This sample size was considered representative and sufficient to detect obesity and related risk factors with a precision rate of $51.02 \%$ in men and $80.39 \%$ in women.

\section{Results}

The obesity risk and obesity non risk prevalence are described in Table 1. Women showed higher values than men obesity risk. The overall prevalence of obesity risk and obesity non risk were men $51.02 \%$ and women $80.39 \%$, women $19.61 \%$.and men $48.98 \%$, respectively. The differences between genders were established for the obesity risk in lifestyle, family history, BMI and family history and BMI. Moreover, in middle-aged groups values in the family history plays vital role for obesity risk were described in Table 2 .

Table I Comparison of men and women obesity

\begin{tabular}{llll}
\hline Middle age & Obesity risk & Obesity non risk & Total \\
\hline Men & $50(51.02 \%)$ & $48(48.98 \%)$ & 98 \\
Women & $82(80.39 \%)$ & $20(19.61 \%)$ & 102 \\
Total & $70(35 \%)$ & $130(65 \%)$ & 200 \\
\hline
\end{tabular}

$X^{2}=41.96293902$

$P=0.0000000040854$

Table 2 Predictive values of risk factors

\begin{tabular}{lllllll}
\hline Middle age & Lifestyle & +ive Men & +ive Women & -ive Men & -ive Women & Total \\
\hline \multirow{2}{*}{ Risk group } & Family History & 30 & 36 & 16 & 12 & 94 \\
& BMI & 12 & 18 & 14 & 10 & 54 \\
Non Risk group & Family History & 8 & 14 & 6 & 4 & 32 \\
Total & BMI & 8 & 4 & 4 & 4 & 20 \\
\hline
\end{tabular}




\section{Discussion and conclusion}

The overall prevalence of obesity risk and obesity non risk in (give the place name) Tamilnadu, India were men 51.02\% and women $80.39 \%$, women $19.61 \%$.and men $48.98 \%$. Men presented higher values of overweight and abdominal obesity prevalence more than women. In both sexes, the main risk factor associated with obesity risk/obesity non risk in adults is the age group 25-45years. In the differences between genders were established for the obesity risk in lifestyle, family history, BMI and family history and BMI. Moreover, in middle-aged groups values in the family history. In both sexes the main risk factors associated with obesity risk are also the age group 25-45years.

\section{Acknowledgements}

None.

\section{Conflict of interest}

The author declares no conflict of interest.

\section{References}

1. Poobalan A, Aucott L. Obesity Among Young Adults in Developing Countries: A Systematic Overview. Curr Obes Rep. 2016;5:2-13.

2. Dee A, Kearns $\mathrm{K}, \mathrm{O}$ Neill $\mathrm{C}$, et al. The direct and indirect costs of both overweight and obesity: a systematic review. BMC Res Notes. 2014;16:242.

3. Ball K, Mishra GD, Crawford D. Social factors and obesity: an investigation of the role of health behaviours. International Journal of Obesity. 2003;27(3):394-403.

4. Neil k Mehta, Virginia W Chang. Mortality Attributable to Obesity among Middle-Aged Adults in the United States. Demography. 2009;46(4):851-872.

5. Power ML, Schulkin J. Sex differences in fat storage, fat metabolism and the health risks from obesity: possible evolutionary origins. $\mathrm{Br} J \mathrm{Nutr}$. 2008;99:931-940.

6. Vernay M, Malon A, Oleko A, et al. Association of socioeconomic status with overall overweight and central obesity in men and women:the French Nutrition and Health Survey 2006. BMC Public Health. 2009;9:21540. 